\title{
Enhancing bio-recovery of bioactive compounds extracted from Citrus medica L. Var. sarcodactylis: optimization performance of integrated of pulsed-ultrasonic/microwave technique
}

\author{
Amer Ali Mahdi ${ }^{1,2,3}$ (]) Marwan M. A. Rashed ${ }^{1,4} \cdot$ Waleed Al-Ansi ${ }^{1,3} \cdot$ Mohamed Ismael Ahmed $^{1,5}$. \\ Mohammed Obadi ${ }^{1} \cdot$ Qi Jiang ${ }^{1,2} \cdot$ Husnain Raza ${ }^{1} \cdot$ Hongxin Wang ${ }^{1,2}$
}

Received: 15 November 2018 / Accepted: 25 February 2019 / Published online: 8 March 2019

(c) Springer Science+Business Media, LLC, part of Springer Nature 2019

\begin{abstract}
This study mainly aimed to optimize a sustainable and green process for extracting bioactive compounds from Foshou fruit by using an integrated technique based on ultrasonic-microwave assisted extraction (UMAE). Response surface methodology (RSM) based on a Box-Behnken design was applied to determine optimal conditions. The following optimized UMAE processing parameters were obtained: sonication time $(96.13 \mathrm{~s})$, microwave power $(305.28 \mathrm{~W})$, and solid/solvent ratio (1:37). Based on a total phenolic compound extraction yield of $9.21 \mathrm{mg}$ gallic acid (GA) equ/g dry weight (DW), a 2,2-diphenyl-1-picrylhydrazyl (DPPH) scavenging activity with a half maximal inhibitory concentration (IC50) of $27.52 \mu \mathrm{g} \mathrm{GA}$ equ, and an antioxidant capacity detected by 2,2'-azino-bis-3-ethylbenzthiazoline-6-sulphonic acid (ABTS) assay of $8.79 \mathrm{mg}$ trolox equ/g DW. The optimized UMAE extract was superior to those obtained using microwave-assisted extraction (MAE) or conventional solvent extraction (CSE) methods. Scanning electron microscopy (SEM) analysis showed that the three extraction methods affected the sample tissue microstructure. Among them, UMAE caused the most marked structural disruption. UPLC-PDA-Q-TOF-MS analysis identified 67 phenolic compounds in the optimized UMAE extract of the Foshou fruit extract. This study indicated that the integrated UMAE technique is a suitable and safe technique to enhance the qualitative and quantitative extraction of phenolic compounds from Foshou fruit. These phenolic compounds can be used as a functional food ingredient in industrial production.
\end{abstract}

\section{Graphical abstract}

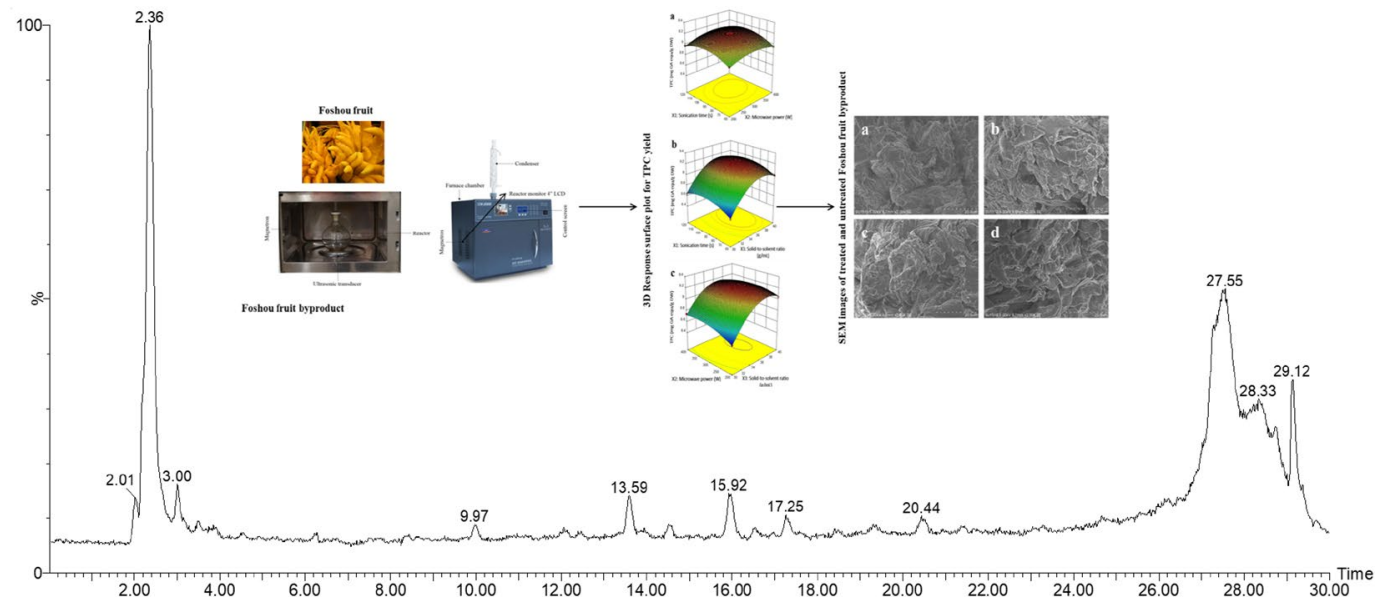

Keywords Citrus medica L. var. sarcodactylis Swingle $\cdot$ Ultrasonic/microwave-assisted extraction $\cdot$ Response surface methodology · Green extraction · Antioxidant · UPLC-PDA-Q-TOF-MS

Extended author information available on the last page of the article 


\section{Introduction}

Citron (Citrus medica L.) is one of the three ancestral Citrus species, together with mandarin orange ( $C$. reticulata Blanco) and pummelo (C. maxima (Burm.) Merr.) [1]. Foshou fruit ( $C$. medica L. var. sarcodactylis Swingle) is classified in Rutaceae family and broadly cultivated in Asian countries. It is usually consumed as a functional food and raw material for some traditional Chinese medicines used to treat chronic diseases because of its content of bioactive compounds, especially phenolic compounds [2].

Phenolic compounds are bioactive, aromatic, and secondary plant metabolites that are widespread in the plant kingdom, have great potential for applications that reduce the risks of several chronic diseases [3, 4], and are closely associated with the effective management of chronic diseases [5]. These compounds have become important because of their associated health benefits, including protection against oxidative stress damage and lifestyle diseases [6]. Luna-Guevara et al. [7] emphasized that phenolic compounds elicit effects against several lifestyle diseases, such as obesity, types of cancers, diabetes mellitus, hypertension, and atherosclerosis. The use of phenolic compounds as bioactive substances has prompted researchers to optimize the efficacy of eco-friendly extraction procedures for green extraction strategies to save time, energy, and total production costs [8]. Green extraction involves innovative extraction technologies with advantages of using safe extraction techniques and clean solvents that do not include toxic chemicals, thereby avoiding the use of organic solvents [6-10].

Phenolic compound extraction via green extraction methods requires the optimization of various extraction parameters, such as raw material amount, and volume of solvent needed [6]. Innovative efforts devoted to improving extraction methods and ensuring compliance with optimization strategies include new extraction processes and alternatives to classical solvents. Alternative extraction processes should be developed on the basis of the modification of current technologies and their protocols [11, 12]. In contrast to classical extraction techniques, ultrasonic-assisted extraction (UAE) has emerged as a promising green extraction technology that fulfills various criteria, including low cost, eco-friendliness, safety, speed, and ease of use [13]. As an important improvement of UAE, ultrasonic/microwaveassisted extraction (UMAE) is an integration of UAE with microwave-assisted extraction (MAE) via simultaneous irradiation [14].

Green extraction should be associated with the use of safe solvents, considering that the exacerbation of environmental pollution caused by the excessive use of volatile and dangerous organic solvents has motivated researchers to develop alternative green solvents. Green solvents are mainly utilized to reduce the use of toxic solvents with their associated negative environmental impacts [8-16]. In this sense, water is considered to be a safe, environmentally sustainable, and green solvent [17].

Green extraction operations should be linked to effective statistical methods to determine the efficiency of extraction techniques, such as response surface methodology (RSM), which includes several arithmetical and statistical methods that can be used to identify the correlations between independent variables and responses. As an experimental methodology, RSM is used to define the effects of independent variables by analyzing the influences of independent variables on responses and to generate a mathematical model $[18,19]$. RSM has been used to optimize extraction procedures for various natural products. Moreover, the resultant models generated by RSM correspond well with actual experimental outcomes [20].

The quality of extracts should be determined by special techniques, such as liquid chromatography coupled with mass spectrometry (LC-MS); LC-MS plays an important role in the determination, characterization, and identification of phenolic compounds in food and the classification and authentication of natural extracts [21]. As well the time-of-flight (TOF) is one of high-resolution mass spectrometry (HRMS) instrumentation and is considered the most generally used analyzer for the LC analysis of phenolic compounds in food matrices [22].

This study focused on finding the optimal conditions for the extraction of total phenolic compounds (TPCs) from Foshou fruit through UMAE as one of the most promising extraction technologies to obtain a safe extract applicable to the food industry. Consequently, the goals of this study were to:

- Investigate the effects of various process parameters on the efficiency of TPC extraction from Foshou fruit using the UMAE process in preliminary single-factor experiments;

- Optimize the UMAE conditions using RSM;

- Compare optimized UMAE extract with those obtained by MAE and CSE in terms of TPC yield, antioxidant activity determined by 2,2-diphenyl-1-picrylhydrazyl free radical-scavenging activity ( $\left.\mathrm{DPPH}^{\bullet}-\mathrm{SA}\right)$ assay, and antioxidant capacity determined by $2,2^{\prime}$-azino-bis-3-ethylbenzthiazoline-6-sulphonic acid radical cation scavenging effect $\left(\mathrm{ABTS}^{\bullet+}\right.$-SE) assay;

- Compare the effects of the three extraction technologies on the Foshou microstructure;

- Identification the phenolic compounds in the optimized UMAE extract of Foshou fruit using the UPLC-PDA-QTOF-MS. 


\section{Materials and methods}

\section{Chemicals}

Gallic acid (CAS:149-91-7) was purchased from Shanghai Yuanye Bio-Technology Co., Ltd. China. Folin phenol reagent (Catalog Number: 73104861), Sodium Carbonate (CAS:497-19-8), Potassium persulfate (CAS:7727-211), Methanol (CAS: 67-56-1) and Ethanol (CAS:64-17-5) were purchased from Sinopharm Chemical Reagent Co., Ltd. (SCR), China. DPPH (CAS:1898-66-4) and Trolox (CAS:53188-07-1) were purchased from Sigma-Aldrich (USA). ABTS (CAS:30931-67-0) was purchased from TCI Europe N.V. (Belgium). All other chemical substances and solvents used were of analytical grade and stored in ideal conditions according to the manufacturer's specifications.

\section{Fruit preparation}

Foshou fruit (C. medica L. var. sarcodactylis) was provided by Zhejiang Golden Hand Biological Technology Co., Ltd. in Jinhua, Zhejiang Province, China in November 2016. The whole Foshou fruits (peels and pulps) were washed with distilled water and cut into small slices with a thickness about $1 \mathrm{~mm}$. The slices were dried to constant weight at $55^{\circ} \mathrm{C}$ in an air oven and then milled using an electric grinder to obtain a fine powder. The fine powder was passed through a 40-mesh sieve to obtain Foshou fruit powder, which was packaged in polyethylene bags under vacuum and stored at $4{ }^{\circ} \mathrm{C}$ until analysis.

\section{Ultrasonic/microwave equipment}

The integrated techno-extraction procedures were performed using a CW-2000 Ultrasonic/microwave Cooperative Extractor/Reactor (Shanxi, Xi' an, China) with an adjustable microwave power range of 10-800 W, a microwave frequency of $2,450 \mathrm{MHz}$, the ultrasonic power level at a constant $50 \mathrm{~W}$, and an ultrasonic frequency of $40 \mathrm{kHz}$. The ultrasonic transducer was directly linked to a reactor flask with a volume of $250 \mathrm{~mL}$. The reactor flask was linked to a reflux condenser. Extractions were performed under a constant ultrasonic power/frequency ratio of $50 \mathrm{~W} / 40 \mathrm{kHz}$.

\section{TPC extraction procedures}

\section{Ultrasonic/microwave-assisted extraction (UMAE)}

To obtain the ultrasonic/microwave-assisted Foshou fruit extract (UMAE), $2 \mathrm{~g}$ of Foshou fruit powder was extracted with distilled water at solid/solvent ratios ranging from 1:20 to $1: 45(\mathrm{~g} / \mathrm{mL})$, microwave power ranged from 200 to $700 \mathrm{~W}$, and sonication time from 30 to $180 \mathrm{~s}$ in a single-factor experiment. In the RSM experiment, $2 \mathrm{~g}$ of Foshou fruit powder was extracted with distilled water (solid/solvent ratios of 1:30, 1:35, and 1:40; g/mL) at microwave power levels of 200, 300 and $400 \mathrm{~W}$, and sonication times of 60,90 and $180 \mathrm{~s}$. The extraction temperature was controlled using a discontinuous model that did not exceed $70{ }^{\circ} \mathrm{C}$ during the sonication time, while the ultrasonic-microwave extractor was operated discontinuously, operated in running-cooling-running stages. The running time did not exceed $60 \mathrm{~s}$ and the extract was cooled for $120 \mathrm{~s}$ between the two running stages. After the extraction process, the Foshou fruit extract was allowed to cool to room temperature. The obtained volume of extract was adjusted to $100 \mathrm{~mL}$ in a standard flask and centrifuged at 4,000 rpm for $20 \mathrm{~min}$. The supernatant solution was filtered under vacuum through the No.1 Whatman filter paper in a Buchner funnel and stored at $4{ }^{\circ} \mathrm{C}$ until further use.

\section{Microwave-assisted extraction (MAE)}

To obtain microwave-assisted Foshou fruit extract (MAE), the CW-2000 Ultrasonic/microwave Cooperative Extractor/Reactor was used in the item of microwave mode (ultrasonic mode turned off). The extraction parameters were used according to Dahmoune et al. [23] with slight modification. Briefly, $2 \mathrm{~g}$ of Foshou fruit powder was extracted by $60 \mathrm{~mL}$ distilled water (solid/solvent ratio $1: 30, \mathrm{~g} / \mathrm{mL}$ ) with a microwave power setting at $400 \mathrm{~W}$ and an extraction time of $120 \mathrm{~s}$. The subsequent steps, including filtration and centrifugation, were performed as described above in UMAE.

\section{Conventional solvent extraction (CSE)}

With a slight modification, the conventional solvent extract (CSE) was prepared according to Spigno et al. [24]. In brief, $2 \mathrm{~g}$ of Foshou fruit powder was extracted with $100 \mathrm{~mL}$ of distilled water (solid/solvent ratio 1:50, g/mL). The mixture was incubated in a shaking water bath for $2 \mathrm{~h}$ at $60^{\circ} \mathrm{C}$ with shaking speed at $110 \mathrm{rpm}$. The subsequent steps including filtration and centrifugation were performed as described in UMAE.

\section{Experimental design}

\section{Single-factor experiments}

The effects of various extraction parameters (sonication time, microwave power, and solid/solvent ratio) were studied using a single-factor experimental design to make a 
preliminary determination of the extraction parameter values to be used in the RSM experiment. The other parameters were maintained at constant values as shown in Table 1 .

\section{Orthogonal experiment design}

To optimize the effects of sonication time (X1), microwave power (X2), and solid/solvent ratio (X3), RSM was coupled with a quadratic model based on the Box-Behnken design (BBD) using Design Expert 10.0.0 (Stat-Ease, Inc., USA) software to determine the optimal parameter values required for maximum TPC yield. The BBD output was 17 runs, including 5 replicates as a center point. The data were subjected to regression analysis to ensure that the obtained responses between the independent variables (X1, X2, and $\mathrm{X} 3$ ) were well fitted with the general second-order polynomial equation (quadratic model) in Eq. (1):

TPC yield $=\beta_{0}+\sum_{i=1}^{k} \beta_{i} x_{i}+\sum_{i=1}^{k} \beta_{i i} x_{i}^{2}+\sum_{1 \leqslant i \leqslant j}^{k} \beta_{i j} x_{i} x_{j}$

where $\beta_{0}$ is the regression coefficient for the intercept (a constant value); $k$ is the number of variables (3); $\beta_{i} \beta_{i i}$, and $\beta_{i j}$ are the coefficients of the linear, quadratic, and interactive terms, respectively; and $x_{i}, x_{i i}$, and $x_{i j}$ represent the coded independent variables. The actual values of factor levels $\left(z_{i}\right)$ were converted to coded values $\left(x_{\mathrm{i}}\right)$ in a range without dimensions $(-1$ to +1$)$ using the following formula:

$x_{i}=\left(z_{i}-z_{i}^{0} / \Delta_{z i}\right) \beta_{d}$

where $\Delta_{z i}$ indicates the difference between the actual value in the central point $\left(z_{i}^{0}\right)$ and the actual value of the lowest or highest level of a variable, and $\beta_{\mathrm{d}}$ is the main coded limit value in the model for each variable [25].

Analysis of variance (ANOVA) was used to evaluate the adequacy of the model by determining the lack of fit, $F$ test value, $p$ value $P r o b>F$, and the coefficient of determination $\left(R^{2}\right)$. Based on the fitted polynomial equation, 3D surface plots were generated using regression coefficients to visualize the relationship between the values of each factor and the response, and to predict the optimal conditions. To validate the model, supplementary extraction trials were performed under the optimal conditions predicted by RSM and the results were compared with the predicted values generated by the regression model.

\section{Analytical methods}

\section{Determination of TPC}

The TPC contents of Foshou fruit extracts were determined using the Folin-Ciocalteu assay according to Chen et al. [26] with some modification. Briefly, $200 \mu \mathrm{L}$ of Foshou fruit
Table 1 Results of single-factor experiments for Ultrasonic/ Microwave-assisted extraction (UMAE) from Foshou fruit

\begin{tabular}{lcclll}
\hline Experiment & No. & $\begin{array}{l}\text { Sonication } \\
\text { time }(\mathrm{s})\end{array}$ & $\begin{array}{l}\text { Microwave } \\
\text { power }(\mathrm{W})\end{array}$ & $\begin{array}{l}\text { Solid/Solvent } \\
\text { ratio }(\mathrm{g}: \mathrm{ml})\end{array}$ & $\begin{array}{l}\text { TPC yield } \\
\text { mg GA equ/g DW }\end{array}$ \\
\hline Effect of sonication time & 1 & 30 & 500 & $1: 30$ & $8.21 \pm 0.20^{\mathrm{ab}}$ \\
& 2 & 60 & 500 & $1: 30$ & $8.55 \pm 0.29^{\mathrm{ab}}$ \\
& 3 & 90 & 500 & $1: 30$ & $8.67 \pm 0.27^{\mathrm{b}}$ \\
& 4 & 120 & 500 & $1: 30$ & $8.43 \pm 0.20^{\mathrm{ab}}$ \\
& 5 & 150 & 500 & $1: 30$ & $8.38 \pm 0.38^{\mathrm{ab}}$ \\
& 6 & 180 & 500 & $1: 30$ & $8.13 \pm 0.04^{\mathrm{a}}$ \\
Effect of microwave power & 1 & 90 & 200 & $1: 30$ & $8.59 \pm 0.10^{\mathrm{a}}$ \\
& 2 & 90 & 300 & $1: 30$ & $9.10 \pm 0.15^{\mathrm{b}}$ \\
& 3 & 90 & 400 & $1: 30$ & $8.76 \pm 0.29^{\mathrm{ab}}$ \\
& 4 & 90 & 500 & $1: 30$ & $8.68 \pm 0.23^{\mathrm{a}}$ \\
& 5 & 90 & 600 & $1: 30$ & $8.61 \pm 0.23^{\mathrm{a}}$ \\
& 6 & 90 & 700 & $1: 30$ & $8.48 \pm 0.13^{\mathrm{a}}$ \\
Effect of solid/solvent ratio & 1 & 90 & 500 & $1: 20$ & $8.19 \pm 0.14^{\mathrm{a}}$ \\
& 2 & 90 & 500 & $1: 25$ & $8.72 \pm 0.17^{\mathrm{b}}$ \\
& 3 & 90 & 500 & $1: 30$ & $8.99 \pm 0.11^{\mathrm{c}}$ \\
& 4 & 90 & 500 & $1: 35$ & $9.18 \pm 0.06^{\mathrm{d}}$ \\
& 5 & 90 & 500 & $1: 40$ & $8.95 \pm 0.17^{\mathrm{c}}$ \\
& 6 & 90 & 500 & $1: 45$ & $8.71 \pm 0.06^{\mathrm{b}}$ \\
\hline
\end{tabular}

Values represent the mean $\pm \mathrm{SD}(\mathrm{n}=3)$

$s$ seconds, $W$ watts, $g: m l$ gram per milliliters, TPC total phenolic compounds, GA equ/g $D W$ gallic acid equivalents/gram dry weight 
extract was added to $5 \mathrm{~mL}(0.2 \mathrm{~N})$ of Folin phenol reagent. After $5 \mathrm{~min}, 4 \mathrm{~mL}$ of $7.5 \%$ sodium carbonate solution was added to the solution. The optical density of the mixture was measured at $765 \mathrm{~nm}$ using a UNICO UV-2100 spectrophotometer (UNICO SCIENTIFIC, HongKong) after incubation at room temperature in the dark for $105 \mathrm{~min}$. The results were expressed as mg of gallic acid equivalents per gram dry weight (mg GA equ/g DW) according to the linear equation for gallic acid y $=0.0093 \mathrm{x}+0.0214$ at an $R^{2}$ value of 0.99 .

\section{Determination of antioxidants activity}

\section{Determination of antioxidant activity by DPPH'-SA assay}

The scavenging activity of Foshou fruit extract against DPPH $^{\bullet}$ was determined according Rashed et al. [27] with a slight modification according $\mathrm{DPPH}^{\bullet}$ methanolic solution $(3.5 \mathrm{~mL}, 60 \mu \mathrm{M})$ was added to $300 \mu \mathrm{L}$ of Foshou fruit extract. After shaking, the reaction was carried out in the dark at room temperature. Absorbance was recorded at $517 \mathrm{~nm}$ after $40 \mathrm{~min}$ of incubation and converted to $\% \mathrm{DPPH} \cdot \mathrm{SA}$ using the following equation:

$\% \mathrm{DPPH}^{\circ}$-SA $=\left[\left(A_{0}-A_{1}\right) / A_{0}\right] \times 100$

where $A_{0}$ is the absorbance of the control and $A_{1}$ is the absorbance of the sample. Trolox solution $(0.375 \mu \mathrm{g} / \mathrm{mL})$ was used as a standard for comparing the results. The $\mathrm{IC}_{50}$ was expressed as $\mu \mathrm{g}$ GA equ.

\section{Determination of antioxidant capacity by $\mathrm{ABTS}^{\circ+}$-SE assay}

To evaluate the antioxidant capacity of Foshou fruit, $\mathrm{ABTS}^{\bullet+} \mathrm{SE}$ assay according to the method of Rashed et al. [28] was used with slight modification. The ABTS stock solution was prepared by dissolving $38.41 \mathrm{mg}$ of the ABTS in $10 \mathrm{~mL}$ of deionized water $(7 \mathrm{mM})$. Potassium persulfate solution $(2.45 \mathrm{mM})$ was prepared by dissolving $6.62 \mathrm{mg}$ of potassium persulfate in $10 \mathrm{~mL}$ of deionized water. Then, $0.5 \mathrm{~mL}$ of the ABTS stock solution was mixed with $0.5 \mathrm{~mL}$ of potassium persulfate solution $(1: 1, \mathrm{v} / \mathrm{v})$ to prepare the $\mathrm{ABTS}^{\bullet+}$ solution. The $\mathrm{ABTS}^{\bullet+}$ solution was kept for $12 \mathrm{~h}$ at room temperature in the dark to obtain a stable blue-green cation radical solution. The stable $\mathrm{ABTS}^{\bullet+}$ solution was diluted with ethanol to an absorbance of $0.700 \pm 0.020$ at $734 \mathrm{~nm}$ before use. Then, $50 \mu \mathrm{L}$ of Foshou fruit extract was added to $3.5 \mathrm{~mL}$ of the $\mathrm{ABTS}^{\bullet+}$ solution and the mixture was allowed to react at room temperature in the dark. The absorbance at $734 \mathrm{~nm}$ was measured relative to a blank (distilled water instead of the extract) after reaction for $10 \mathrm{~min}$. Trolox was used as a standard to plot a Trolox calibration curve at concentrations of $2.25,4.50,6.75,9.00,11.25$, 13.5 , and $16.5 \mu \mathrm{g} / \mathrm{ml}$ Trolox. Results were expressed as mg Trolox equivalents per $\mathrm{g}$ dry weight (mg Trolox equ/g
DW) according to Zhang et al. [29] using the linear equation $\mathrm{y}=-0.033 \mathrm{x}+0.6531$ and an $R^{2}$ value of 0.99 .

\section{UPLC-PDA-Q-TOF-MS analysis}

The UPLC-PDA-Q-TOF-MS analysis were done according to the method described by He et al. [30], with some modifications. The analysis were carried out on a WATERS ACQUITY UPLC device, a WATERS ACQUITY PDA detector (set at 200 and $600 \mathrm{~nm}$.), and a WATERS UPLC BEH C18 column $(1.7 \mu \mathrm{m}, 2.1 \mathrm{~mm}$, I.D., $100 \mathrm{~mm})$ at $45^{\circ} \mathrm{C}$ (temperature of column oven) (Waters Corp., Milford, USA). The injection volume of the sample was $1 \mu \mathrm{l}$. The mobile phase comprised of acetonitrile (A) and water with $0.1 \%$ formic acid (B) with a flow rate of $0.3 \mathrm{ml} / \mathrm{min}$. Mass spectrometry executed on a WATERS MALDI SYNAPT Q-TOF MS device with electrospray ionization mass spectrometry (ESI-MS) (Waters Corp., Milford, USA).

The ESI-MS spectra were obtained in negative ion mode in the mass range of 20 to $1500 \mathrm{~m} / \mathrm{z}$. The voltage of capillary was $3.0 \mathrm{kV}$, while $20 \mathrm{~V}$ was the voltage of sample cone and collision energy was $6.0 \mathrm{eV}$. The desolvation gas temperature was $400{ }^{\circ} \mathrm{C}$ with $700 \mathrm{~L} / \mathrm{h}$ flow, and the temperature of source block was $100{ }^{\circ} \mathrm{C}$ and the flow of cone gas was $50 \mathrm{~L} / \mathrm{h}$. All processes controlled and data analysis by MarkerLynx software (Waters, Milford, MA, USA). The widely accepted accuracy for confirmation of compositions was set at less than $10 \mathrm{ppm}$. The phenolic compounds were identified by comparing the molecular weight according to MS data which extracted by MarkerLynx software with the databases of the European Bioinformatics Institute and ChemSpider [31, 32].

\section{Scanning electron microscopy (SEM) observation}

Foshou fruit powder specimens (extracted and unextracted samples) were visually observed using a scanning electron microscope (SU 1510, Hitachi Corp., Tokyo, Japan) to investigate the effects of the different extraction methods on the Foshou fruit surface microstructure. After extraction, powder residues were dried in an oven at $50{ }^{\circ} \mathrm{C}$ until a constant weight was obtained before SEM analysis. The SEM observation were done at an accelerating beam voltage of $5.00 \mathrm{kV}$ under high vacuum conditions, and a working distance of $9.5-9.8 \mathrm{~mm}$.

\section{Statistical analysis}

Each extraction trial and all analyses were conducted in triplicate and all the data in this paper are reported as the mean \pm SD. Microsoft Office Excel 2016 software was used to generate the linear equations and the $\mathrm{IC}_{50}$ values for the $\mathrm{DPPH}^{\bullet} \mathrm{SA}$ assay. IBM SPSS Statistics software (Version 20.0. Armonk, NY: IBM Corp.) was used to determine the 
significance of differences between means at the $95 \%$ confidence level $(P \leq 0.05)$ using one-way analysis and Duncan's test.

\section{Results and discussions}

\section{Single-factor experiments}

The results of single factor experiments are summarized in Table 1. The TPC yield from Foshou fruit extract was the highest ( $8.67 \mathrm{mg} \mathrm{GA}$ equ/g DW) at a sonication time of $90 \mathrm{~s}$, constant microwave power of $500 \mathrm{~W}$, and a solid/solvent ratio of $1: 30(\mathrm{~g} / \mathrm{mL})$. With the sonication time increased to $180 \mathrm{~s}$, the yield decreased to $8.13 \mathrm{mg} \mathrm{GA}$ equ/g DW due to thermal degradation of the phenolic compounds. Based on these outcomes, we chose a sonication time of $90 \mathrm{~s}$ for the subsequent single-factor experiments, while sonication times of 60,90 , and $120 \mathrm{~s}$ were used for RSM experiments. The microwave power level had a significant effect on the TPC yield. With an increasing in microwave power from $200 \mathrm{~W}$ to $300 \mathrm{~W}$, the TPC yield increased from $8.59 \mathrm{mg}$ GA equ/g DW to $9.10 \mathrm{mg} \mathrm{GA}$ equ/g DW (the highest TPC yield), respectively. With higher microwave power levels of $400,500,600$, and $700 \mathrm{~W}$, the TPC yields decreased slightly to $8.76,8.68,8.61$, and $8.48 \mathrm{mg} \mathrm{GA}$ equ/g DW, respectively. Statistically, there were no significant differences between the TPC yields at microwave power levels of 200, 500, 600, and $700 \mathrm{~W}$, probably due to the degradation of phenolic compounds when using high levels of microwave power during the extraction process [33]. We chose a microwave power level of $300 \mathrm{~W}$ for use in subsequent single-factor experiments, while microwave power levels of 200, 300, and $400 \mathrm{~W}$ were used in RSM experiments. With increasingly wide solid/solvent ratios of 1:20, 1:25, 1:30, and 1:35, the TPC yields increased $(8.198 .72,8.99$, and $9.18 \mathrm{mg} \mathrm{GA}$ equ/g DW, respectively). A further widening of the solid/ solvent ratio caused a decrease in the TPC yield. The highest TPC yield of $9.18 \mathrm{mg} \mathrm{GA}$ equ/g DW was obtained with a solid/solvent ratio of 1:35. Based on these results, we chose solid/solvent ratios of 1:30, 1:35, and 1:40 for the RSM experiments.

\section{Modeling of UMAE}

\section{Optimization and prediction of extraction parameter values using RSM}

To enhance the TPC yield, we used RSM based BBD to determine the optimal combination of the independent variables. The parameters included sonication time (X1), microwave power (X2), and solid/solvent ratio (X3) at a fixed sonication power/frequency ratio of $50 \mathrm{~W} / 40 \mathrm{kHz}$. The coded and uncoded levels of the independent variables shown in Table 2. As well actual and predicted values of the dependent variables (response) are shown in Table 3. The actual values of TPC yield ranged from 8.56 to $9.20 \mathrm{mg} \mathrm{GA}$ equ/g DW, while the predicted values ranged from 8.57 to $9.18 \mathrm{mg} \mathrm{GA}$ equ/g DW. Based on multiple regression analysis, a final second-order polynomial equation in terms of coded factors with disregard the non-significant terms $(P>0.01)$ was created to obtain the maximum TPC yield from Foshou fruit (Eq. 4).

$$
\begin{aligned}
T P C= & 9.18+0.039 A+0.036 B+0.20 C+0.017 A B \\
& +0.000 A C-0.040 B C-0.12 A^{2}-0.083 B^{2} \\
& -0.25 C^{2}
\end{aligned}
$$

The optimal predicted extraction conditions to achieve the highest TPC yield (9.21 mg GA equ/g DW) were as follows: $\mathrm{X} 1=96.1285 \mathrm{~s}, \mathrm{X} 2=305.278 \mathrm{~W}$, and $\mathrm{X} 3=1: 37$. The regression coefficients of the mathematical model describing the TPC yield as a function of A, B, and C are shown in Table 4 . $F$ test and $p$ values were used to analyze the significance of each coefficient. Bezerra et al. [25] confirmed that a model will be well fitted to the experimental data if it shows a significant regression and a non-significant lack of fit. In this study, the model $F$ value (163.44) was significant, and the $p$-value Prob $>F$ was $<0.0001(<0.05)$. Furthermore, the lack of fit $F$-value of $<0.001$ was not significant, and the $p$-value $P r o b>F$ was 0.51 ( $>0.05$ ). The value of $R^{2}$ was (0.9953), indicating that the model satisfactorily described the real relationships between the chosen variables. The Adjusted R-squared $\left(R_{A d j}^{2}\right)$ value in the model $(0.9892)$ was close to $R^{2}$. Moreover, the Predicted R-squared $\left(R_{\text {pred }}^{2}\right)$ value (0.9648) was in reasonable agreement with $R_{a d j}^{2}$. This confirms that the model was highly significant, where the difference was $<0.2$. The regression coefficient from the experimental data and the adjusted data were reasonably close to 1 , which indicated a high degree of correlation between the observed and predicted values.

The 3-D response surface plots of the interactions between the factors $\mathrm{X} 1, \mathrm{X} 2$, and $\mathrm{X} 3$ are shown in Fig. 1 . All maximum points as critical points were found within the experimental region, indicating that they represented the optimal values. The overlap between $\mathrm{X} 1$ and $\mathrm{X} 2$ is shown in Fig. 1a. These two factors had a positive effect on the TPC yield with the same degree of proximity. $\mathrm{X} 3$ produced a curve that was broader than the X1 and X 2 curves, indicating that it had the strongest effect.

\section{Validation of the predictive model}

We obtained the optimal values of the selected independent factors by solving the regression equation and analyzing the contour and response surface plots. To evaluate the 
validity of the model in Eq. (4), the extraction of TPC from of Foshou fruit was performed in triplicate under the optimal conditions, which included; X1 (96 s), X2 (305 W), and X3 (1:37). There was no significant difference between the experimental (9.21 mg GA equ/g DW) and predicted (9.22 mg GA equ/g DW) mean TPC yield values; hence, this model can be used to optimize TPC extraction from Foshou fruit.

\section{Investigation of the UMAE, MAE, and CSE effects on the yield of TPC}

Results of TPC that obtained with the optimized UMAE conditions were compared with those obtained using the MAE and CSE techniques. The highest TPC yield of $9.21 \mathrm{mg} \mathrm{GA}$ equ/g DW was obtained using UMAE, followed by the yields from MAE ( $9.09 \mathrm{mg}$ GA equ/g DW) and CSE (8.72 mg GA equ/g DW), with significant differences between both UMAE and MAE, UMAE and CSE. Overall, the TPC yields obtained using water as a solvent were higher than those obtained by Liu et al. [34] and Jayaprakasha, Patil [35] who obtained TPC yields of $5.86 \mathrm{mg}$ GA equ/g DW using $60 \%$ ethanol and $7.18 \mathrm{mg}$ GA equ/g DW using $80 \%$ methanol, respectively.

\section{Antioxidants activity}

\section{Antioxidant activity determination by DPPH॰-SA assay}

The $\mathrm{IC}_{50}$ values calculated based DPPH ${ }^{\bullet}$-SA assay differed significantly between the UMAE, MAE, and CSE. UMAE reached the lower $\mathrm{IC}_{50}(27.52 \mu \mathrm{g}$ GA equ) compared to the MAE (30.36 $\mu \mathrm{g}$ GA equ) and CSE (31.17 $\mu \mathrm{g}$ GA equ). Castillo et al. [36] studied the antioxidant activity of the $C$. medica and found that the $\mathrm{IC}_{50}(\mathrm{DPPH})$ was approximately $29.45 \mu \mathrm{g}$ GA equ, which represented a lower antioxidant activity than was obtained with UMAE in this study, but higher than the activities we obtained with MAE and CSE.
Table 2 Experimental Factor levels (coded and uncoded)

\begin{tabular}{lllllll}
\hline Factors & Coded & \multicolumn{5}{l}{ Uncoded } \\
\hline (X1) Sonication time (s) & -1 & 0 & +1 & 60 & 90 & 120 \\
(X2) Microwave power (W) & -1 & 0 & +1 & 200 & 300 & 400 \\
(X3) Solid/Solvent ratio (g:ml) & -1 & 0 & +1 & $1: 30$ & $1: 35$ & $1: 40$ \\
\hline
\end{tabular}

$s$ seconds, $W$ watts, $g: m l$ gram per milliliters

\begin{tabular}{llllll}
\hline & Factor 1 & Factor 2 & Factor 3 & \multicolumn{2}{l}{ TPC $(\mathrm{mg}$ GA equ/g DW) } \\
\cline { 5 - 6 } Run & Sonication time $(\mathrm{s})$ & $\begin{array}{l}\text { Microwave } \\
\text { power }(\mathrm{W})\end{array}$ & $\begin{array}{l}\text { Solid/solvent ratio } \\
(\mathrm{g}: \mathrm{ml})\end{array}$ & Actual & Predicted \\
\hline 1 & & 200 & $1: 35$ & $8.93 \pm 0.22$ & 8.92 \\
2 & 60 & 400 & $1: 40$ & $9.05 \pm 0.23$ & 9.05 \\
3 & 90 & 300 & $1: 40$ & $8.99 \pm 0.31$ & 8.98 \\
4 & 90 & 200 & $1: 40$ & $9.04 \pm 0.36$ & 9.06 \\
5 & 90 & 400 & $1: 30$ & $8.74 \pm 0.23$ & 8.72 \\
6 & 120 & 300 & $1: 40$ & $9.07 \pm 0.20$ & 9.06 \\
$7 *$ & 90 & 300 & $1: 35$ & $9.20 \pm 0.18$ & 9.18 \\
$8^{*}$ & 90 & 300 & $1: 35$ & $9.16 \pm 0.19$ & 9.18 \\
9 & 60 & 300 & $1: 30$ & $8.56 \pm 0.25$ & 8.57 \\
10 & 90 & 200 & $1: 30$ & $8.57 \pm 0.19$ & 8.57 \\
$11^{*}$ & 90 & 300 & $1: 35$ & $9.15 \pm 0.38$ & 9.18 \\
12 & 120 & 400 & $1: 35$ & $9.06 \pm 0.13$ & 9.07 \\
13 & 120 & 200 & $1: 35$ & $8.97 \pm 0.14$ & 8.96 \\
14 & 60 & 400 & $1: 35$ & $8.95 \pm 0.32$ & 8.96 \\
$15 *$ & 90 & 300 & $1: 35$ & $9.18 \pm 0.26$ & 9.18 \\
$16^{*}$ & 90 & 300 & $1: 35$ & $9.20 \pm 0.31$ & 9.18 \\
17 & 120 & 300 & $1: 30$ & $8.64 \pm 0.19$ & 8.65 \\
\hline
\end{tabular}

$s$ seconds, $W$ watts, $g: m l$ gram/milliliters, $T P C$ total phenolic compounds, $G A$ equ/g $D W$ gallic acid equivalents/gram dry weight

*Central point; values represent the mean \pm SD $(n=3)$ 
Table 4 Analysis of variance (ANOVA) for the experimental results obtained by using ultrasonic/microwave-assisted extraction (UMAE)

\begin{tabular}{|c|c|c|c|c|c|c|}
\hline Source & Sum of squares & $\mathrm{df}$ & Mean square & F value & $\mathrm{p}$ value Prob. $>$ F & \\
\hline Model & 0.74 & 9 & 0.082 & 163.44 & $<0.0001$ & Significant \\
\hline A-Sonication time & 0.012 & 1 & 0.012 & 23.99 & 0.0018 & \\
\hline B-Microwave power & 0.011 & 1 & 0.011 & 21.00 & 0.0025 & \\
\hline C-Solid/Solvent ratio & 0.34 & 1 & 0.34 & 671.44 & $<0.0001$ & \\
\hline$A B$ & $1.225 \mathrm{E}-003$ & 1 & $1.225 \mathrm{E}-003$ & 2.45 & 0.1618 & \\
\hline$A C$ & 0.000 & 1 & 0.000 & 0.000 & 1.0000 & \\
\hline$B C$ & $6.400 \mathrm{E}-003$ & 1 & $6.400 \mathrm{E}-003$ & 12.78 & 0.0090 & \\
\hline$A^{2}$ & 0.058 & 1 & 0.058 & 116.59 & $<0.0001$ & \\
\hline$B^{2}$ & 0.029 & 1 & 0.029 & 57.58 & 0.0001 & \\
\hline$C^{2}$ & 0.25 & 1 & 0.25 & 505.78 & $<0.0001$ & \\
\hline Residual & $3.505 \mathrm{E}-003$ & 7 & $5.007 \mathrm{E}-004$ & & & \\
\hline Lack of fit & $1.425 \mathrm{E}-003$ & 3 & $4.750 \mathrm{E}-004$ & 0.91 & 0.5100 & Not significant \\
\hline Pure error & $2.080 \mathrm{E}-003$ & 4 & $5.200 \mathrm{E}-004$ & & & \\
\hline Cor total & 0.74 & 16 & & & & \\
\hline Mean 8.97 & Std. Dev. 0.022 & C.V. $\% 0.25$ & $\mathrm{R}^{2} 0.9953$ & $\mathrm{R}_{\text {Adj }}^{2} 0.9892$ & & $\mathrm{R}_{\text {Pred }}^{2} 0.9648$ \\
\hline
\end{tabular}

\section{Antioxidant capacity determination by $\mathrm{ABTS}^{+}$-SE assay}

The antioxidant capacity values of the UMAE, MAE, and CSE extracts determined in term of $\mathrm{ABTS}^{\bullet+}$-SE assay were significantly different. The UMAE achieved the highest activity ( $8.79 \mathrm{mg}$ Trolox equ/g DW), followed by MAE (8.39 mg Trolox equ/g DW), and CSE (8.17 mg Trolox equ/g DW). Sun et al. [37] determined the antioxidant capacities of the main citrus species and the results ranged from 104.64 to $269.40 \mathrm{mg} / \mathrm{g}$ Trolox equivalent. In another investigation, Menichini et al. [38] reported that the $\mathrm{IC}_{50}$ of $C$. medica $\mathrm{L}$. cv Diamante (Rutaceae) peel extract in terms of $\mathrm{ABTS}^{\bullet+}$-SE (\%)was $3.48 \mathrm{mg} / \mathrm{mL}$.

Double simultaneous irradiation (ultrasound/microwave) causes synergic effects on the extraction of bioactive compounds from plant matrices. Ultrasound dramatically increases the extraction efficiency through the cavity phenomenon that induces the release of soluble compounds from plant matrices by crashing cell walls.

At the same time, microwave quickly heats whole plant matrices, thereby causing the transmigration of dissolved molecules. Furthermore, the simultaneous irradiation enhances solvent permeation into the matrix and increases the solubility of compounds. Additionally, the power levels required by UMAE are lower than those of two single energy sources alone [11-14].

Our results showed that UMAE was considered the best technique. It allowed increasing the TPC yields by $5.62 \%$ and $1.32 \%$ compared with those of CSE and MAE, respectively. UMAE also improved the antioxidant activities by $11.71 \%$ and $2.60 \%$ compared with those of CSE and MAE, respectively. By contrast, UMAE increased the antioxidant capacities by $7.56 \%$ and $4.77 \%$ compared with those of CSE and MAE, respectively. UMAE shortened the extraction time by $98.66 \%$ and $19.89 \%$ compared with those of CSE and MAE, respectively.

\section{UPLC-PDA-Q-TOF-MS analysis}

According to the analysis of the optimized UMAE extract of Foshou fruit using the technique of chromatography, 67 phenolic compounds appeared in the extract (Table 5). The base peak intensity (BPI) chromatogram of optimized UMAE extract of Foshou fruit (negative ion mode) shown in Fig. 2.

Interestingly, the optimized UMAE extract of Foshou fruit contains many compounds that have important properties such as anti-cancer, anti-inflammatory, anti-diabetic, and antimicrobial, as an example 4'-hydroxychalcone is one of Chalcones, and has a potential effect on the prevention and treatment of the inflammatory and cancer [39]. The norathyriol found in Mango fruit and has an anti-cancer activity, where decreased the viability of MCF-7 breast cancer cells [40]. Tian et al. [41] confirmed that the bellidifolin compound significantly decreased in the fasting blood glucose sample, in addition to improving the oral glucose tolerance and decresing of the fasting serum insulin. In the study conducted by Qiu, Chen [42], ophioglonin showed slight anti-hepatitis B virus surface antigen activity at $25 \mu \mathrm{M}$. 2,2',4'-trihydroxy-6'-methoxy-3',5'-dimethylchalcone possessed an antiprotozoal activity against Leishmania donovani at $\mathrm{IC}_{50} 7.5 \mu \mathrm{g} / \mathrm{mL}$ of methanolic extract of Psorothamnus polydenius [43]. Bauhinoxepins A found in Bauhinia saccocalyx roots and showed antimycobacterial activity [44]. 4-Hydroxycordoin is an isopentenyloxychalcone and has a clear ability against three major periodontal pathogen bacteria Prevotella intermedia, Porphyromonas gingivalis, 

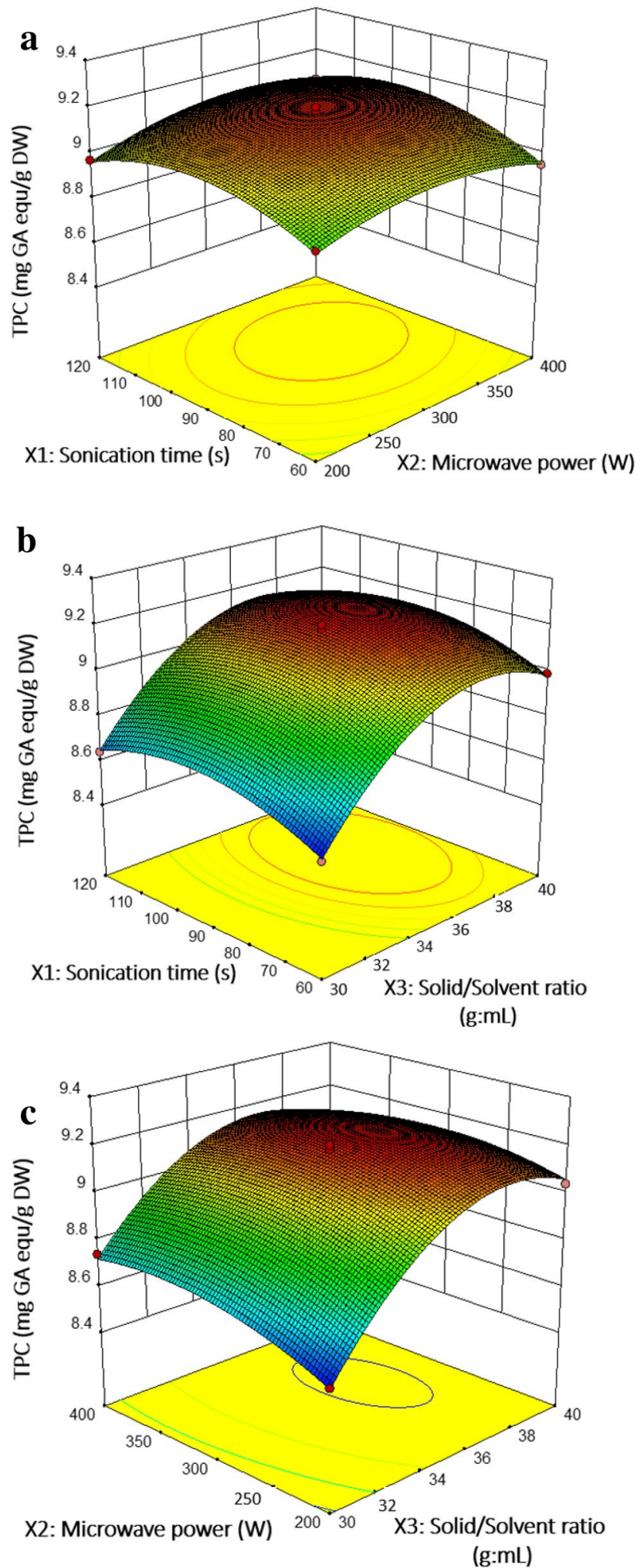

Fig. 1 3D Response surface plot for TPC yield a sonication time (s) with microwave power (W); b sonication time (s) with solid/solvent ratio $(\mathrm{g}: \mathrm{mL}) ; \mathbf{c}$ microwave power $(\mathrm{W})$ with solid/solvent ratio $(\mathrm{g}: \mathrm{mL})$ and Fusobacterium nucleatum, as well anti-inflammatory effect [45]. Pterolinus D is one of benzofurans, was found in extract of Pterocarpus santalinus, Pterolinus D showed significant inhibition as an anti-inflammatory [46]. Abyssinone $\mathrm{C}$ isolated from Erythrina abyssinica and showed moderate cytotoxic activity against the human colorectal cancer cell line at $\mathrm{IC}_{50} 15.1 \mu \mathrm{M}$ [47]. The Blancoxanthone was isolated from Calophyllum blancoi and exhibited significant anti-coronavirus activity [48]. Brasixanthone B is a xanthones found for the first time in Calophyllum brasilienses and showed significant inhibitory activity against Epstein-Barr virus in Raji cells [49]. 4'-demethyldeoxypodophyllotoxin showed activity against the human epidermoid carcinoma and P-388 lymphocytic leukemia [50]. The kweichowenol B isolated from Uvaria kweichowensis leaves and showed antitumour activity based on yellow tetrazolium assay [51]. Erybraedin A had high activity against the BC and NCI-H187 cells ( $\mathrm{IC}_{50}$ $2.9 \mu \mathrm{g} / \mathrm{ml}$ of Erythrina stricta roots [52].

\section{SEM analysis}

The SEM observation showed varying damage to the surface microstructures of the plant cellular tissues due to different extraction methods between UMAE, MAE, and CSE. The combination of disruption of plant tissues by acoustic cavitation caused by ultrasonic/microwaves and solvent flow into plant cell tissues facilitated by thermal stress resulting from microwave irradiation can improve the effectiveness of extraction [14-53].

SEM images of treated and untreated Foshou fruit powder are shown in Fig. 3. Images of untreated Foshou fruit powder and powder after extraction by UMAE, MAE, and CSE under the optimized conditions are shown in Fig. 3a-d, respectively. The SEM images showed remarkable changes in the microstructure of the Foshou fruit powder samples after extraction. Ultrasonic/microwave-assisted extraction through the cavitation phenomenon helped to decaythe sample plant tissues, while microwave power led to further disintegration of the plant tissue. By contrast, the conventional solvent extraction had only a slight effect on the tissue microstructure, with no oserve of disintegration.

\section{Conclusions}

In conclusion, this investigation has enhanced green-procedures extraction to maximize the total phenolic content (TPC) yield from Foshou fruit using water as an environment-friendly solvent and ultrasonic/microwave-assisted as integrated technology. Response surface methodology based 
Table 5 The content of phenolic compounds in the Foshou fruit extraction according to the UPLC-PDA-Q-TOF-MS analysis

\begin{tabular}{|c|c|c|c|c|}
\hline No. & Phenolic compounds & ChemSpider ID & Average mass (Da) & Molecular formula \\
\hline 1 & $p$-Hydroxyphenylbut-3-ene-2-one & 86341 & 162.185 & $\mathrm{C}_{10} \mathrm{H}_{10} \mathrm{O}_{2}$ \\
\hline 2 & 3-hydroxyphenyl propanoate & 213621 & 166.174 & $\mathrm{C}_{9} \mathrm{H}_{10} \mathrm{O}_{3}$ \\
\hline 3 & Isoacetovanillone & 86383 & 166.174 & $\mathrm{C}_{9} \mathrm{H}_{10} \mathrm{O}_{3}$ \\
\hline 4 & 3-(2-hydroxyphenyl)propanoic acid & 850 & 166.174 & $\mathrm{C}_{9} \mathrm{H}_{10} \mathrm{O}_{3}$ \\
\hline 5 & Paeonol & 10621 & 166.174 & $\mathrm{C}_{9} \mathrm{H}_{10} \mathrm{O}_{3}$ \\
\hline 6 & 4-(4-Hydroxyphenyl)-2-butanol & 88266 & 166.217 & $\mathrm{C}_{10} \mathrm{H}_{14} \mathrm{O}_{2}$ \\
\hline 7 & Ferulic acid & 689 & 194.184 & $\mathrm{C}_{10} \mathrm{H}_{10} \mathrm{O}_{4}$ \\
\hline 8 & 2-(4-Hydroxyphenyl)-3-methylbutyric acid & 100571 & 194.227 & $\mathrm{C}_{11} \mathrm{H}_{14} \mathrm{O}_{3}$ \\
\hline 9 & Acetosyringone & 16280 & 196.200 & $\mathrm{C}_{10} \mathrm{H}_{12} \mathrm{O}_{4}$ \\
\hline 10 & 2',6'-Dimethoxy-4'-hydroxyacetophenone & 391208 & 196.200 & $\mathrm{C}_{10} \mathrm{H}_{12} \mathrm{O}_{4}$ \\
\hline 11 & Eugenin & 9777 & 206.195 & $\mathrm{C}_{11} \mathrm{H}_{10} \mathrm{O}_{4}$ \\
\hline 12 & Leptorumol & 26631404 & 206.195 & $\mathrm{C}_{11} \mathrm{H}_{10} \mathrm{O}_{4}$ \\
\hline 13 & Pisonin E & 26631542 & 220.178 & $\mathrm{C}_{11} \mathrm{H}_{8} \mathrm{O}_{5}$ \\
\hline 14 & 4'-Hydroxychalcone & 4445525 & 224.255 & $\mathrm{C}_{15} \mathrm{H}_{12} \mathrm{O}_{2}$ \\
\hline 15 & 2,3-Bis(hydroxymethyl)-7-hydroxy-6-methoxy-1-tetralone & 26384422 & 252.263 & $\mathrm{C}_{13} \mathrm{H}_{16} \mathrm{O}_{5}$ \\
\hline 16 & Norathyriol & 4444975 & 260.199 & $\mathrm{C}_{13} \mathrm{H}_{8} \mathrm{O}_{6}$ \\
\hline 17 & Norswertianin & 4444977 & 260.199 & $\mathrm{C}_{13} \mathrm{H}_{8} \mathrm{O}_{6}$ \\
\hline 18 & Athyriol & 4444941 & 274.226 & $\mathrm{C}_{14} \mathrm{H}_{10} \mathrm{O}_{6}$ \\
\hline 19 & Swertianin & 4444980 & 274.226 & $\mathrm{C}_{14} \mathrm{H}_{10} \mathrm{O}_{6}$ \\
\hline 20 & Bellidifolin & 4444942 & 274.226 & $\mathrm{C}_{14} \mathrm{H}_{10} \mathrm{O}_{6}$ \\
\hline 21 & Ophioglonin & 9636002 & 314.246 & $\mathrm{C}_{16} \mathrm{H}_{10} \mathrm{O}_{7}$ \\
\hline 22 & Wedelolactone & 4445124 & 314.246 & $\mathrm{C}_{16} \mathrm{H}_{10} \mathrm{O}_{7}$ \\
\hline 23 & 2,2',4'-Trihydroxy-6'-methoxy-3',5'-dimethylchalcone & 9946086 & 314.332 & $\mathrm{C}_{18} \mathrm{H}_{18} \mathrm{O}_{5}$ \\
\hline 24 & (E)-4,2',4'-Trihydroxy-6'-methoxy-3',5'-dimethylchalcone & 26363219 & 314.332 & $\mathrm{C}_{18} \mathrm{H}_{18} \mathrm{O}_{5}$ \\
\hline 25 & Cefatrizine & 4918615 & 462.503 & $\mathrm{C}_{18} \mathrm{H}_{18} \mathrm{~N}_{6} \mathrm{O}_{5} \mathrm{~S}_{2}$ \\
\hline 26 & Pterolinus C & 26629959 & 316.348 & $\mathrm{C}_{18} \mathrm{H}_{20} \mathrm{O}_{5}$ \\
\hline 27 & Cajanol & 26392261 & 316.305 & $\mathrm{C}_{17} \mathrm{H}_{16} \mathrm{O}_{6}$ \\
\hline 28 & (+)-Pisiferic acid & 142446 & 316.435 & $\mathrm{C}_{20} \mathrm{H}_{28} \mathrm{O}_{3}$ \\
\hline 29 & Triptobenzene A & 58827400 & 316.435 & $\mathrm{C}_{20} \mathrm{H}_{28} \mathrm{O}_{3}$ \\
\hline 30 & Pterolinus E & 26630078 & 318.321 & $\mathrm{C}_{17} \mathrm{H}_{18} \mathrm{O}_{6}$ \\
\hline 31 & Cylindol A & 8601421 & 318.278 & $\mathrm{C}_{16} \mathrm{H}_{14} \mathrm{O}_{7}$ \\
\hline 32 & 2-Hydroxy-6-[2-(3,4-dihydroxyphenyl-5-methoxy)-2-oxoethyl]benzoic acid & 26633602 & 318.278 & $\mathrm{C}_{16} \mathrm{H}_{14} \mathrm{O}_{7}$ \\
\hline 33 & Griffithane A & 26636847 & 318.364 & $\mathrm{C}_{18} \mathrm{H}_{22} \mathrm{O}_{5}$ \\
\hline 34 & (-)-(4S,5S,10R)-10,12,18-Trihydroxy-7-oxo-20-norabieta-8,11,13-triene & 26390807 & 318.407 & $\mathrm{C}_{19} \mathrm{H}_{26} \mathrm{O}_{4}$ \\
\hline 35 & abyssinone I & 390670 & 322.354 & $\mathrm{C}_{20} \mathrm{H}_{18} \mathrm{O}_{4}$ \\
\hline 36 & Bauhinoxepin A & 9898347 & 322.354 & $\mathrm{C}_{20} \mathrm{H}_{18} \mathrm{O}_{4}$ \\
\hline 37 & 8-Prenyldaidzein & 23550835 & 322.354 & $\mathrm{C}_{20} \mathrm{H}_{18} \mathrm{O}_{4}$ \\
\hline 38 & $(-)$-Phaseolin & 58145272 & 324.370 & $\mathrm{C}_{20} \mathrm{H}_{20} \mathrm{O}_{4}$ \\
\hline 39 & 4-Hydroxycordoin & 4732316 & 324.370 & $\mathrm{C}_{20} \mathrm{H}_{20} \mathrm{O}_{4}$ \\
\hline 40 & $N$-feruloylserotonin & 4766454 & 352.384 & $\mathrm{C}_{20} \mathrm{H}_{20} \mathrm{~N}_{2} \mathrm{O}_{4}$ \\
\hline 41 & (-)-Demethoxylpinoresinol & 8489888 & 328.359 & $\mathrm{C}_{19} \mathrm{H}_{20} \mathrm{O}_{5}$ \\
\hline 42 & (5R)-5-Hydroxy-7-(4"'-hydroxy-3'"-methoxyphenyl)-1-phenyl-3-heptanone & 136694 & 328.402 & $\mathrm{C}_{20} \mathrm{H}_{24} \mathrm{O}_{4}$ \\
\hline 43 & Juglanin B & 24721805 & 328.402 & $\mathrm{C}_{20} \mathrm{H}_{24} \mathrm{O}_{4}$ \\
\hline 44 & Pterolinus D & 26630077 & 334.321 & $\mathrm{C}_{17} \mathrm{H}_{18} \mathrm{O}_{7}$ \\
\hline 45 & Bussealin B & 26381829 & 334.364 & $\mathrm{C}_{18} \mathrm{H}_{22} \mathrm{O}_{6}$ \\
\hline 46 & Triptobenzene K & 58170306 & 342.386 & $\mathrm{C}_{20} \mathrm{H}_{22} \mathrm{O}_{5}$ \\
\hline 47 & Kadsurenin $\mathrm{K}$ & 2340650 & 342.386 & $\mathrm{C}_{20} \mathrm{H}_{22} \mathrm{O}_{5}$ \\
\hline 48 & Neotriptophenolide & 117981 & 342.429 & $\mathrm{C}_{21} \mathrm{H}_{26} \mathrm{O}_{4}$ \\
\hline 49 & 7-(4"'-Hydroxy-3"'-methoxyphenyl)-5-methoxy-1-phenyl-3-heptanone & 28533010 & 342.429 & $\mathrm{C}_{21} \mathrm{H}_{26} \mathrm{O}_{4}$ \\
\hline 50 & Dihydrocurcumin & 4522656 & 370.396 & $\mathrm{C}_{21} \mathrm{H}_{22} \mathrm{O}_{6}$ \\
\hline
\end{tabular}


Table 5 (continued)

\begin{tabular}{|c|c|c|c|c|}
\hline No. & Phenolic compounds & ChemSpider ID & Average mass (Da) & Molecular formula \\
\hline 51 & Candidachalcone & 26334170 & 370.396 & $\mathrm{C}_{21} \mathrm{H}_{22} \mathrm{O}_{6}$ \\
\hline 52 & Abyssinone $\mathrm{C}$ & 28532919 & 372.369 & $\mathrm{C}_{20} \mathrm{H}_{20} \mathrm{O}_{7}$ \\
\hline 53 & Glycosmisic acid & 22913536 & 372.369 & $\mathrm{C}_{20} \mathrm{H}_{20} \mathrm{O}_{7}$ \\
\hline 54 & Vladinol D & 30786452 & 374.384 & $\mathrm{C}_{20} \mathrm{H}_{22} \mathrm{O}_{7}$ \\
\hline 55 & 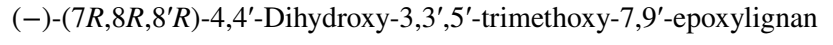 & 26630118 & 374.427 & $\mathrm{C}_{21} \mathrm{H}_{26} \mathrm{O}_{6}$ \\
\hline 56 & 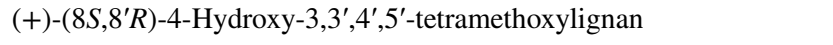 & 26629055 & 374.471 & $\mathrm{C}_{22} \mathrm{H}_{30} \mathrm{O}_{5}$ \\
\hline 57 & Guaiacylglycerol $\beta$-coniferyl ether & 4947720 & 376.400 & $\mathrm{C}_{20} \mathrm{H}_{24} \mathrm{O}_{7}$ \\
\hline 58 & (7R)-7-Hydroxylariciresinol & 8197966 & 376.400 & $\mathrm{C}_{20} \mathrm{H}_{24} \mathrm{O}_{7}$ \\
\hline 59 & Blancoxanthone & 9878297 & 378.418 & $\mathrm{C}_{23} \mathrm{H}_{22} \mathrm{O}_{5}$ \\
\hline 60 & Brasixanthone B & 8537718 & 378.418 & $\mathrm{C}_{23} \mathrm{H}_{22} \mathrm{O}_{5}$ \\
\hline 61 & 4'-demethyldeoxypodophyllotoxin & 141208 & 384.379 & $\mathrm{C}_{21} \mathrm{H}_{20} \mathrm{O}_{7}$ \\
\hline 62 & Kweichowenol B & 9524559 & 384.379 & $\mathrm{C}_{21} \mathrm{H}_{20} \mathrm{O}_{7}$ \\
\hline 63 & $(-)$-medioresinol & 158029 & 388.411 & $\mathrm{C}_{21} \mathrm{H}_{24} \mathrm{O}_{7}$ \\
\hline 64 & Simulanol & 20057219 & 388.411 & $\mathrm{C}_{21} \mathrm{H}_{24} \mathrm{O}_{7}$ \\
\hline 65 & (-)-5'-methoxyisolariciresinol & 34448446 & 390.427 & $\mathrm{C}_{21} \mathrm{H}_{26} \mathrm{O}_{7}$ \\
\hline 66 & Abyssinone VI & 4444631 & 392.487 & $\mathrm{C}_{25} \mathrm{H}_{28} \mathrm{O}_{4}$ \\
\hline 67 & Erybraedin A & 20006335 & 392.487 & $\mathrm{C}_{25} \mathrm{H}_{28} \mathrm{O}_{4}$ \\
\hline
\end{tabular}

Da Dalton

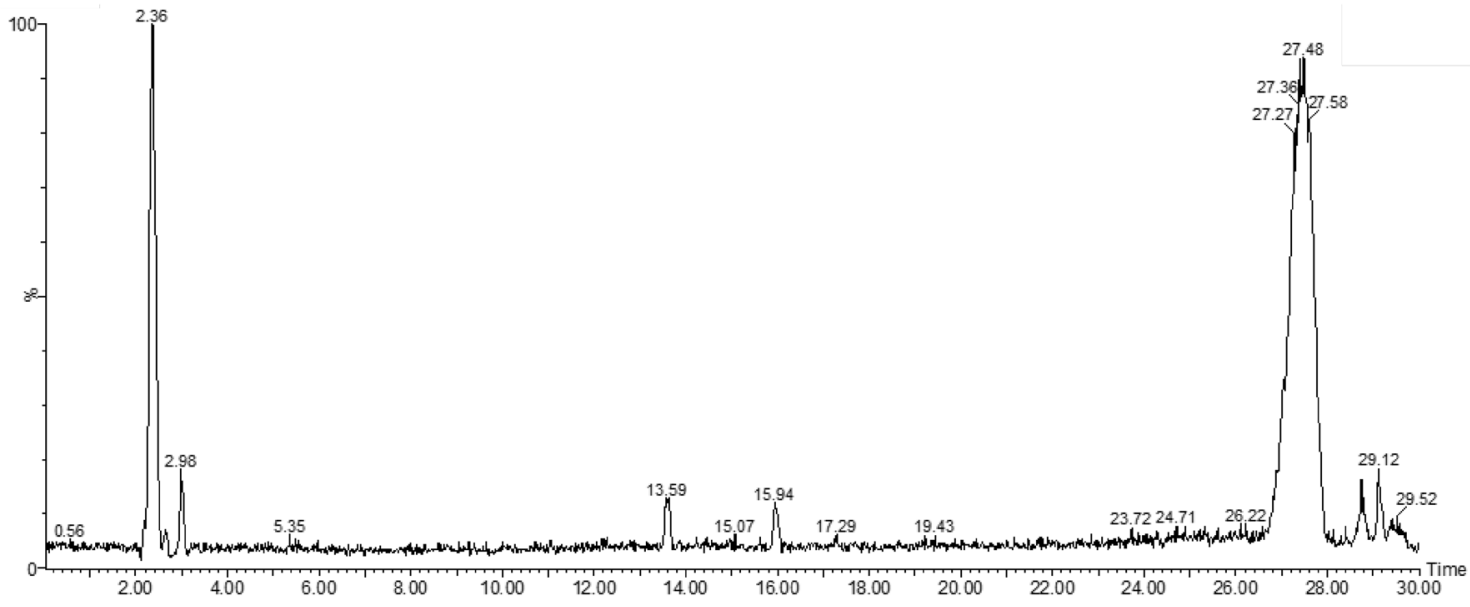

Fig. 2 The base peak intensity (BPI) chromatogram of optimized UMAE extract of Foshou fruit in the negative ion mode

a Box-Behnken design was successfully used to optimize the performance of ultrasonic/microwave-assisted technique and enhance the extraction processes. Findings of this work showed that the integrated ultrasonic/microwave-assisted extraction was more efficient than the microwave-assisted extraction or conventional solvent extraction as obtaining the highest TPC yield and antioxidant activity from Foshou fruit. In sum, Foshou fruit can be considered a good source of TPC that possess a high antioxidant activity, and thus can be used as safe food additives instead of synthetic additives. In the same context, ultrasonic/microwave-assisted extraction can be used as a safe integrated technique that does not require the use of harmful solvents. 

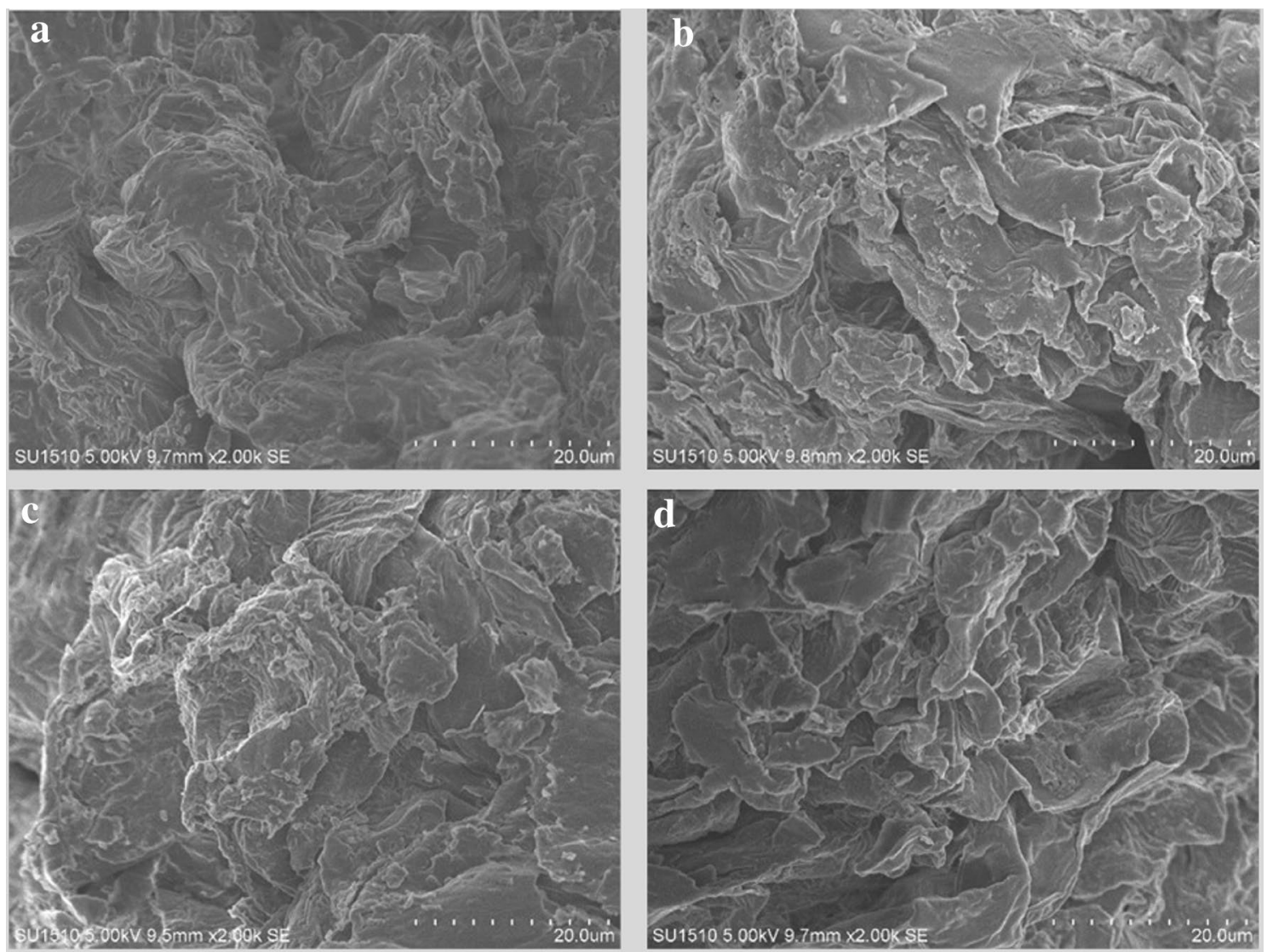

Fig. 3 Scanning electron microscope images of Foshou fruit powders untreated (a), after extraction under the optimized conditions of ultrasonic/ microwave-assisted extraction (b), microwave-assisted extraction (c) and conventional solvent extraction (d)

Acknowledgements This research was financially supported by the China Scholarship Council (CSC), Beijing, China and carried out in the Laboratory of the National Engineering Research Center for Functional Food at Jiangnan University, Wuxi, China.

\section{Compliance with ethical standards}

Conflict of interest The authors declare no conflict of interest.

\section{References}

1. C. Ramadugu, M.L. Keremane, X. Hu, D. Karp, C.T. Federici, T. Kahn, M.L. Roose, R.F. Lee, Sci. Hortic. 195, 124-137 (2015)

2. Z. Wu, H. Li, Y. Yang, Y. Zhan, D. Tu, Ind. Crops Prod. 46, 311-316 (2013)

3. F. Shahidi, P. Ambigaipalan, J. Funct. Foods 18, 820-897 (2015)

4. M.M. Özcan, S. Doğu, N. Uslu, J. Food Meas. Charact. 12, 902905 (2018)

5. L. Shen, H.F. Ji, H.Y. Zhang, Biochem. Biophys. Res. Commun. 362, 543-545 (2007)

6. K. Ameer, H.M. Shahbaz, J.H. Kwon, Compr. Rev. Food Sci. Food Saf. 16, 295-315 (2017)

7. M.L. Luna-Guevara, J.J. Luna-Guevara, P. Hernández-Carranza, H. Ruíz-Espinosa, C.E. Ochoa-Velasco, In: Studies in Natural
Products Chemistry, ed. By A. Rahman (Elsevier B.V., 2018) p. 79

8. M. Plaza, C. Turner, Trends Anal. Chem. 76, 39-54 (2015)

9. B.K. Tiwari, Trends Anal. Chem. 71, 100-109 (2015)

10. S. Armenta, S. Garrigues, M. de la Guardia, TrAC, Trends Anal. Chem. 71, 2-8 (2015)

11. F. Chemat, N. Rombaut, A.G. Sicaire, A. Meullemiestre, A.S. Fabiano-Tixier, M. Abert-Vian, Ultrason. Sonochem. 34, 540-560 (2017)

12. Y. Liu, S. Wei, M. Wu, S. Yang, J. Food Meas. Charact. 12, 967$973(2018)$

13. J. Azmir, I. Zaidul, M. Rahman, K. Sharif, A. Mohamed, F. Sahena, M. Jahurul, K. Ghafoor, N. Norulaini, A. Omar, J. Food Eng. 117, 426-436 (2013)

14. H.K. Kala, R. Mehta, K.K. Sen, R. Tandey, V. Mandal, Trends Anal. Chem. 85, 140-152 (2016)

15. S. Prabakaran, L. Ramu, S. Veerappan, B. Pemiah, N. Kannappan, J. Food Meas. Charact. 11, 1531-1541 (2017)

16. J. Płotka-Wasylka, M. Rutkowska, K. Owczarek, M. Tobiszewski, J. Namieśnik, Trends Anal. Chem. 91, 12-25 (2017)

17. G. Brunner, J. Supercrit. Fluid 47, 373-381 (2009)

18. G. Astray, B. Gullón, J. Labidi, P. Gullón, Ind. Crops Prod. 92, 290-299 (2016)

19. S. Nag, N. Sit, J. Food Meas. Charact. 12, 1734-1743 (2018)

20. J.L. Pilkington, C. Preston, R.L. Gomes, Ind. Crops Prod. 58, 15-24 (2014)

21. P. Lucci, J. Saurina, O. Núñez, TrAC, Trends Anal. Chem. 88, $1-24(2017)$ 
22. A. Kaufmann, TrAC, Trends Anal. Chem. 63, 113-128 (2014)

23. F. Dahmoune, L. Boulekbache, K. Moussi, O. Aoun, G. Spigno, K. Madani, Ind. Crops Prod. 50, 77-87 (2013)

24. G. Spigno, L. Tramelli, D.M. De Faveri, J. Food Eng. 81, 200-208 (2007)

25. M.A. Bezerra, R.E. Santelli, E.P. Oliveira, L.S. Villar, L.A. Escaleira, Talanta 76, 965-977 (2008)

26. G.L. Chen, S.G. Chen, Y.Y. Zhao, C.X. Luo, J. Li, Y.Q. Gao, Ind. Crops Prod. 57, 150-157 (2014)

27. M.M. Rashed, Q. Tong, M.H. Abdelhai, M.A. Gasmalla, J.B. Ndayishimiye, L. Chen, F. Ren, Ultrason. Sonochem. 29, 39-47 (2016)

28. M.M. Rashed, Q. Tong, A. Nagi, J. Li, N.U. Khan, L. Chen, A. Rotail, A.M. Bakry, Ind. Crops Prod. 100, 236-245 (2017)

29. L. Zhang, Z.C. Tu, H. Wang, Z.F. Fu, Q.H. Wen, H.X. Chang, X.Q. Huang, Food Res. Int. 70, 101-109 (2015)

30. W. He, M. Zeng, J. Chen, Y. Jiao, F. Niu, G. Tao, S. Zhang, F. Qin, Z. He, J. Agric. Food Chem. 64, 171-177 (2015)

31. European Molecular Biology Laboratory European Bioinformatics Institute. http://www.ebi.ac.uk. Accessed 25 Feb 2017

32. Royal Society of Chemistry ChemSpider. http://www.chemspider .com. Accessed 25 Feb 2017

33. C. Proestos, M. Komaitis, LWT Food Sci. Technol. 41, 652-659 (2008)

34. H. Liu, N. Qiu, H. Ding, R. Yao, Food Res. Int. 41, 363-370 (2008)

35. G. Jayaprakasha, B.S. Patil, Food Chem. 101, 410-418 (2007)

36. S. Castillo, J. Dávila-Aviña, N. Heredia, S. Garcia, Food Sci. Biotechnol. 26, 453-459 (2017)

37. Y. Sun, L. Qiao, Y. Shen, P. Jiang, J. Chen, X. Ye, J. Food Sci. 78, 37-42 (2013)

38. F. Menichini, R. Tundis, M.R. Loizzo, M. Bonesi, D. D’Angelo, P. Lombardi, V. Mastellone, J. Enzyme Inhib. Med. Chem. 31, 1270-1276 (2016)

39. B. Orlikova, D. Tasdemir, F. Golais, M. Dicato, M. Diederich, Biochem. Pharmacol. 82, 620-631 (2011)
40. A.S. Wilkinson, M.W. Taing, J.T. Pierson, C.N. Lin, R.G. Dietzgen, P.N. Shaw, M.J. Gidley, G.R. Monteith, S.J. Robertsthomson, Food Funct. 6, 1847-1854 (2015)

41. L.Y. Tian, X. Bai, X.H. Chen, J.B. Fang, S.H. Liu, J.C. Chen, Phytomedicine 17, 533-539 (2010)

42. L.P. Qiu, K.P. Chen, Fitoterapia 84, 140-157 (2013)

43. M.M. Salem, K.A. Werbovetz, J. Nat. Prod. 68, 108-111 (2005)

44. P. Kittakoop, S. Nopichai, N. Thongon, P. Charoenchai, Y. Thebtaranonth, Helv. Chim. Acta 87, 175-179 (2004)

45. M. Feldman, S. Tanabe, F. Epifano, S. Genovese, M. Curini, D. Grenier, J. Nat. Prod. 74, 26-31 (2011)

46. S.F. Wu, F.R. Chang, S.Y. Wang, T.L. Hwang, C.L. Lee, S.L. Chen, C.C. Wu, Y.C. Wu, J. Nat. Prod. 74, 989-996 (2011)

47. L. Cui, P.T. Thuong, H.S. Lee, D. Njamen, J.T. Mbafor, Z.T. Fomum, J. Lee, Y.H. Kim, W.K. Oh, Planta Med. 74, 422-426 (2008)

48. Y.C. Shen, L.T. Wang, A.T. Khalil, L.C. Chiang, P.W. Cheng, Chem. Pharm. Bull. 36, 244-247 (2005)

49. I. Chihiro, I. Masataka, M. Yoshitaka, C.F. Valdir, M. Teruo, T. Harukuni, N. Hoyoku, F. Hiroshi, J. Nat. Prod. 65, 267-272 (2002)

50. R. Jiang, J.R. Zhou, P.M. Hon, S.L. Li, Y. Zhou, L.L. Li, W. Ye, H. Xu, P. Shaw, P.P. But, J. Nat. Prod. 70, 283-286 (2007)

51. Q.M. Xu, Z.M. Zou, L.Z. Xu, S.L. Yang, Chem. Pharm. Bull. 53, 826-828 (2005)

52. T. Rukachaisirikul, A. Saekee, C. Tharibun, S. Watkuolham, A. Suksamrarn, Arch. Pharmacal Res. 30, 1398-1403 (2007)

53. M.M. Rashed, A.D. Ghaleb, J. Li, A. Nagi, Y. Hua-wei, Z. Wenyou, Q. Tong, ACS Sustain. Chem. Eng. 6, 1639-1649 (2018)

Publisher's Note Springer Nature remains neutral with regard to jurisdictional claims in published maps and institutional affiliations.

\section{Affiliations}

\section{Amer Ali Mahdi 1,2,3 - Marwan M. A. Rashed ${ }^{1,4} \cdot$ Waleed AI-Ansi ${ }^{1,3} \cdot$ Mohamed Ismael Ahmed $^{1,5}$. Mohammed Obadi $^{1} \cdot$ Qi Jiang ${ }^{1,2} \cdot$ Husnain Raza ${ }^{1} \cdot$ Hongxin Wang ${ }^{1,2}$}

\section{Hongxin Wang}

hxwang@jiangnan.edu.cn

1 State Key Laboratory of Food Science and Technology, School of Food Science and Technology, Jiangnan University, 1800 Lihu Road, Wuxi 214122, China

2 National Engineering Research Center for Functional Food, Jiangnan University, 1800 Lihu Road, Wuxi 214122, China

3 Department of Food Science and Technology, Faculty of Agriculture, Sana'a University, Sana'a, Yemen
4 Solid-State Fermentation Resource Utilization Key Laboratory of Sichuan Province, College of Life Science \& Food Engineering, Yibin University, 8 Jiusheng Road Wuliangye Avenue, Yibin, Sichuan 644000, China

5 Department of Food Science and Technology, Nyala Technical College South Darfur, Nyala, Sudan 